\title{
Please publish me
}

\section{J Mayberry}

\section{What do the editorial board and referees look for in papers submitted to the Postgraduate Medical Journal?}

T he Postgraduate Medical Journal is committed to ongoing medical education across the whole range of specialties and in many different countries. Clearly the requirements of clinicians vary with different settings. Will an epidemiologist in South East Asia have the same requirements as a North American internist? The answer, clearly, is no. However, a major purpose of the journal is to keep doctors up-to-date with specialties outside their own area of practice. It is the principle which underlies the future planning of the journal and guides referees in making their judgments on whether papers submitted to the journal should be accepted or rejected.

What are the editorial board and referees looking for when they consider a paper for publication in the Postgraduate Medical Journal? The criteria depends to some extent on the nature of the paper.

\section{REVIEW ARTICLES}

Review articles need to be up-to-date and provide practical and clear guidance where possible for the clinician. Areas of uncertainty need to be documented and referenced. The views expressed in favour of one form of treatment as opposed to another should be soundly based and referenced. Of course, as practising clinicians we all have developed certain biases over the years. When a review article discusses such personal preferences the authors are encouraged to make it clear that this is exactly what they are-personal preferences and prejudices. However, such views need to be kept to a minimum. They only have a small part in contemporary clinical practice and would be hard to defend against criticism. In the "Best practice" series, authors have adopted such critical approaches to the evaluation of data which they have incorporated into the review. It is the critical methodology which has ensured the popularity of the series.

\section{CASE REPORTS}

Case reports are a sharp contrast to the comprehensive review article. We all see interesting patients at times, but why should they be reported in the Postgraduate Medical Journal? The editorial board has adopted a clear policy towards case reports. They need to show:

- An unusual clinical development, and/or

- A new insight into a well recognised clinical problem

This clearly excludes the simple reporting of rare cases. A case report needs to have an educational message. It needs either to expand our knowledge of that disease process or of its pathophysiology or treatment. Simply submitting the 20 th case of a syndrome is unlikely to result in successful publication. The editorial board and referees will need evidence of how the case contributes to our understanding of the disease.

In recent years, case reports have flagged up new diseases, as in the case of AIDS, and given a better understanding of pathology as with familial adenomatous polyposis. Innovative treatment has also been introduced through case reports, but questions as to the ethics of such an approach need to be considered. In some countries bioethics committees will specifically consider such approaches and formally "licence" them. In others, this is not the case and such reports should deal with the ethical issues behind innovative treatments.

The journal has adopted stringent rules about patient identification when dealing with case reports. They can only be published with the consent of the patient. The content of a case report goes to the heart of patient confidentiality. A breach of this confidentiality is a breach of patient trust and an example of professional misconduct. It is therefore critically important that patient consent to publication is obtained before submission to the journal.

\section{SELF ASSESSMENT QUESTIONS (SAQS)}

Similar rules apply to SAQs. Their purpose is to provide up-to-date education about clinical conditions. They do not need to be about rare diseases, but they do need to act as a vehicle by which clinicians can test their present knowledge and learn about new aspects of diagnosis and treatment. Again, clinical rarity is not an important aspect of the case; indeed, at times, it detracts from the educational value of the question. SAQs should not be seen as "failed case reports". They have different functions and a rejected case report is unlikely to make a useful SAQ.

\section{IMAGES}

What about medical images? The journal is keen to publish images which have a clear educational message, or are aesthetically interesting or relate to historical aspects of medicine in the broadest term. A picture which "shocks" is unlikely to be published simply for its horror value.

\section{ORIGINAL ARTICLES}

Original articles are always welcome at the journal. We continue to believe in the value of clinical research and to encourage its impact on health care. For most doctors this is the reason they took up clinical practice. All of us should be enthusiastic about applying scientific methodology to patient investigation, care, and treatment and so ensure the provision of the best service that we can achieve. The journal is here to trumpet the achievements of such research. Send us your papers! As practising clinicians, the editorial board will welcome them.

\section{SPECIALIST AREAS OF PUBLICATION}

We also wish to develop specialist areas of publication which deal with issues in ethnic health, and the legal and ethical aspects of practice. During the coming years we will also expand our section on medical history.

\section{THE FUTURE . . .}

What is the future for the Postgraduate Medical Journal? It is one where the practising clinician will be able to find up-todate guidance on clinical management and be challenged by opportunities for his or her better education. It is for this reason that the journal will continue to support research on how best to educate doctors and will expand such work through its web version-PMJ Online.

Postgrad Med J 2003;79:427

Correspondence to: Dr John Mayberry, Editor, Leicester General Hospital; pmj@btinternet.com 